\title{
O SISTEMA DE FORMAÇÃO DE ADULTOS E AS UNIVER- SIDADES POPULARES NA ALEMANHA OCIDENTAL
}

\author{
Dr. Manfred Kuder \\ Diretor do Colégio para estrangeiros da \\ Universidade de Bonn
}

A instrução cultural de adultos torna-se essencial sobretudo em tempos de grandes transformaçōes sociais, como é o caso no nosso século, da industrialização e democratização. A cada um de nós deve ser dada a possibilidade de encontrar uma resposta às perguntas de sua época. Essa instrução que é dada pela universidade popular tem o fim dle comunicar ao indivíduo os fatos concretos de sua vida e de seu trabalho que èle necessita para compreender o enigmático conjunto das circunstâncias na economia e na politica. Deve tornar-selhe possivel, por si próprio, orientar-se neste mundo sem correr 0 perigo de ser dominado por peritos e gerentes administradores que lhe tiram tôda a responsabilidade própria. A formação de adultos ajuda-lhe a criar os meios espirituais para obter uma posição de espírito independente na sua profissão e na vida particular, politica e social, no trabalho e no tempo livre. A instrução de adultos é hoje o terceiro entre os ramos de ensino primário, secundário e profissional. Ela é promovida não só pelas universidades populares, mas também pela igreja e pelos sindicatos, por rádio, televisāo, cinema, clubes desportivos e sobretudo pela imprensa, por bibliotecas populares e livros de preço acessivel. Esta instrução voluntária é completamente livre, patente a todos, independente de idade e de sexo, de raça e de credo religioso, de filiação politica ou de posição social. Não se supōe a obtenção de diploma. Domina a tarefa educadora que insiste sôbre a participação ativa do aluno. A conferència ou preleção constitui só a montra da universidade popular atrás da qual se concentra o trabalho pròpriamente dito, o curso prático e os estudos em grupo, nos quais existe a diferença entre leitores e alunos só pelos diferentes graus de saber e de preparaçāo e nāo pela contribuiçāo.

A princípio distingue-se da escola por lidar com pessôas experimentadas e adultas, e da universidade por querer servir não à causa cientifica mas sim ao homem. Na instruçāo de adultos portanto, o homem prevalece sôbre a causa que ainda assim nāo perde o seu valor, mas precisa dum conhecimento mais intensivo dela para tornar evidente a sua importância em relaçāo ao homem. Assim no trabalho espiritual comum de tôda a assistência, os elementos científicos são projetados sôbre o ecran do humano fundamental. Neste sentido a 
universidade popular não tem por princípio o ensino acadêmico isolado ou a popularização da ciência. Ela familiariza também os seus alunos com o modo de emprêgo de outras instituições culturais como as bibliotecas populares, rádio, televisão e cinema. Há muitas aulas práticas que se dedicam aos estudos da influência dos grandes meios de comunicação. A escolha dos docentes é livre, o programa é composto liberalmente segundo a variedade da vida cultural e espiritual.

O estado democrático é o estado duma sociedade pluralista. Os membros desta sociedade tendem para a formação da cultura segundo o seu meio de vida. Tal é o caso das profissōes, dos sindicatos, dos partidos politicos, mas principalmente dos grupos religiosos e ideológicos. Seria errado propagar a primazia do estado perante a cultura que se desenvolve nestes grupos. Assim temos hoje três tipos de formação de adultos na Alemanha: a formação livre geral, a formação religiosa e terceiramente a formação sujeita a certos grupos de que falarei mais adiante.

Entre os fatores de formaçāo que, além da família e da profissāo influem no jovem, a universidade popular ocupa um lugar importante. Esta posição deverá por isso ser amplificada. Esta universidade entretanto não fornece uma formação de especialização nas diversas camadas profissionais embora ela inclua vários cursos de especialização no seu programa. Será também sempre a sua tarefa combinar a cultura geral com a formação especial, pois o homem de hoje não se restringe no decurso de sua existência a uma só profissāo, mas sim, quer aumentar as suas possibilidades e por isso mudar de profissão. A formação especializada nunca será capaz de proporcionar a cultura geral necessária que ultrapassa os limites da ocupação.

Há estreita colaboração entre a escola superior e a universidade popular. Esta nāo poderia trabalhar sem os inúmeros professôres, docentes e assistentes que lecionam nela. Além disso os professôres universitários promovem numa outra cidade, durante uma ou duas semanas, preleçōes, aulas práticas e conferências. Desta maneira os professôres são obrigados a adaptar a sua linguagem científica à mentalidade da nova assistência.

A universidade popular pōe em correlação o modo de aprender sistemático das escolas primárias e secundárias e as impressōes espontâneas da vida real dos adultos. Ela tem a difícil tarefa de ligar os diferentes aspectos de nossa atividade, resultados da divisāo do trabalho.

A formação de adultos esteve sujeita a muitas transformações durante os cento e tantos anos desde a sua fundação. Ela é o produto e espelho da democratização da nossa sociedade. Teve as suas origens nas tendências revolucionárias de grupos e camadas sociais prejudicados contra poderes conservativos. Origem e evolução estão ligados tão estreitamente à democratização da sociedade industrial, que o problema do seu futuro nāo pode ser discutido sem o do futuro 
da democracia. A formação livre e geral começou com o desenvolvimento da indústria moderna. A industrialização destruiu a ordem social dos séculos passados, aglomerou a maioria da população em cidades e acelerou o desenvolvimento nāo só da vida profissional como também de toda a sociedade. Êste processo manifestou-se na politica pela introdução de certas formas fundamentais da democracia parlamentar, na economia social pelo aumento da segurança social para camadas sociais inferiores e pelo enfraquecimento gradual dos antigos privilégios economicos e no setor cultural também pela eliminação de privilégios e pela criação de possibilidades de formação para aquêles que até aí nāo as tinham. Assim formação e educação alcançaram uma importância central para poder fazer frente às novas liberdades e obrigações. E nisto que a formaçāo moderna de adultos tem a sua origem. Trata-se do desenvolvimento da personalidade emancipada espiritualmente que nāo se quer submeter a uma autoridade sem critica. Na primeira fase da evolução o objetivo da formação de adultos era a contribuiçāo para a criaçāo das condiçōes fundamentais de cultura para a democracia e a vida industrial. Ela tentou acabar com o analfabetismo motivado por um sistema de instruçāo defeituosa. Êste sistema, entretanto, foi aperfeiçoado e as camadas dantes prejudicadas tomam hoje parte na responsabilidade política. Depois disso a sociedade tem hoje a obrigação muito mais dificil de elevar a sua estrutura e os seus membros social e culturalmente a um nivel correspondente às novas exigências. Os conhecimentos elementares já nāo chegam para dominar os problemas da vida moderna. O movimento do nosso tempo acelerou-se de tal maneira, que também uma forma modernisada de ensino se torna insuficiente já no espaço de tempo da vida de uma geração única.

O problema não é resolvido por uma aglomeração enciclopédica da matéria, embora a situaçāo na vida politica, cultural e social exija conhecimentos mais amplos e profundos. Isto consiste mais na orientação da matéria espiritual e dos métodos para a nova situação social e nas relações múltiplas. Deixem-me sublinhar de novo que cada instrução especializada numa certa profissāo sem os aspectos multilaterais duma formação geral orientada em direção à sociedade é incapaz de preparar os homens para a nova situação do desenvolyimento da vida profissional, que requer flexibilidade e visão de conjunto.

Tentarei agora falar resumidamente sôbre os vários tipos de formação dos adultos na Alemanha:

A universidade popular noturna é a mais conhecida pelo público. Com cêrca de mil e cem universidades populares e cêrca de quatro mil e duzentos postos exteriores ela é, já no que se refere à abundância, a maior de tôdas. A universidade popular interna, uma forma de instrução de adultos levada à Alemanha dos paises escandinavos, impõs-se quase exclusivamente em regiōes campestres. Universidades internas que se dedicam a estudantes das cidades, há pou- 
cas. Tendo como fim os mesmos resultados da universidade popular noturna, as universidades internas têm a possibilidade de aprofundar, em cursos que variam de oito dias a seis meses de duração, o sucesso dos seus esforços de instrução por meio da convivência mútua num lar.

As bibliotecas populares, quase sempre tidas como bibliotecas públicas comunais, esforçam-se, com resultado cada vez maior, por obter 0 interêsse das pessoas por meio de livros valiosos e bons. $O$ estado e outras instituiçōes públicas pōem à disposição das bibliotecas populares consideráveis meios para a sua ampliação, procurando da melhor maneira guarnecer cada aldeia com boa literatura. Há pouco tempo emprega-se nas regiōes campestres, e para o fornecimento dos arredores das cidades os assim chamados "bookmobils".

A instrução confessional dos adultos foi fundada para obter um meio de contacto entre a igreja e o mundo. As academias protestantes e católicas depressa se tornaram importantes. Em cursos de uma semana, em excursōes e fins de semana em comum, estas instituiçōes procuram entrar em contacto com representantes de todos os grupos sociais e ideológicos possiveis, e discutir com êles sôbre questões e problemas da vida fundamentais ou atuais, partindo sempre do ponto de vista da sua religiāo. Impulsos importantes para a nossa vida politica e religiosa tiveram suas origens nesses encontros.

Os centros de estudos de instrução católica de adultos trabalham, como as universidades populares noturnas, em cursos, em aulas práticas e em conferências. Em princípio, e quanto aos alunos, são também patentes a todos, colocando, porém, segundo o seu objetivo, sempre o ponto de vista católico em primeiro plano.

Em seminários sociais, promovidos em grande número e sobretudo em regiōes campestres por ambas as religiōes, tenta-se animar pessôas mais novas para a atividade social e de Ihes dar os elementos necessários ao conhecimentos das regras fundamentais da sociologia cristā, que as farão capazes de cumprir os seus deveres para com a nação, a sociedade e a comunidade da igreja. A sua forma de trabalho é também o curso noturno, variado de vez em quando por excursões nos fins de semana. Seminários sôbre o matrimônio, promovidos semelhantemente por ambas as religiöes, servem sobretudo para a preparação da juventude para um matrimônio cristão conscientemente vivido.

Em princípio, as bibliotecas católicas ou protestantes funcionam mais ou menos como as bibliotecas populares acima mencionadas. Só na escolha dos livros é que seguem outros critérios, segundo a sua missão religiosa.

Falemos da instrução de adultos sujeita a certos grupos. Nas escolas federais da associação dos sindicatos da Alemanha e nas instituições correspondentes dos sindicatos industriais, os empregados são preparados em cursos breves ou a longo prazo para tomar posse duma 
funçāo pública e para a colaboraçāo nos grêmios. Também um outro organismo social, a associação federal dos empregadores tenta, através de cursos e escolas semelhantes, preparar os funcionários de responsabilidade média ou elevada em economia e comércio, além de transmitir-lhes conhecimentos da especialidade que lhes possibilitarão assumir sua responsabilidade perante a nação.

O mesmo também se observa, sempre segundo o ponto de vista do grupo dominante, nas atividades das sociedades cooperativas, dos sindicatos rurais e, cada vez mais, também na indústria. A tôdas estas associaçōes cabe um pouco de responsabilidade pelo progresso da nossa sociedade e do nosso estado - e assim tôdas elas promovem a instrução legítima de adultos se bem que sujeita a um certo ponto de vista. Justamente sôbre a grande variedade dêste tipo poder-se-ia ainda mencionar muitos detalhes.

A instruçāo de adultos na Alemanha mostra ao leigo bem como ao que já a conhece, uma multiplicidade desconcertante. Uma curta exposiçāo - e sobretudo um resumo como êste - pode dar sòmente um esbôço incompleto dos diferentes esforços. Só tentamos portanto, distinguir entre os tipos e as formas essenciais.

Para a universidade popular nāo há restriçāo de temas. Ocupa-se com todos os problemas para o tratamento dos quais existe uma necessidade cultural objetiva ou subjetiva. Não pode ser excluido nenhum tema por razões ideológicas, sociais, de politica local ou cultural. Assim os seus planos de trabalho abrangem todos os temas.

Tôda a universidade popular noturna mostra ser de qualidade especial, que desenvolveu um mètodo considerável de fazer nascer verdadeiras necessidades de informação e cultura.

Neste sentido é inevitável fazer cuidadosas e proveitosas estatísticas dos participantes, pelas quais se pode, pelo menos esboçadamente verificar as necessidades e estudá-las. Na escolha dos docentes mostra-se então a publicidade e comunidade necessárias quando exercem essa função não só pedagogos de profissão mas também homens e mulheres de tôdas as camadas profissionais, que devem possuir aptidāo e talento naturais para a formaçāo de adultos.

Têm de ser capazes de saber distinguir, à base de conhecimentos aprofundados, entre a exposição de fatos e a atitude pessoal, e também de saber justificar posiçōes contrárias. Os lentes da universidade popular têm de se sentir comprometidos à busca da verdade. A universidade popular está patente a todos os participantes que sāo sinceros para com os de outra opinião. Só assim ela pode ser uma instituição para o encontro de opiniōes contrárias. $O$ que foi dito acêrca de restriçāo dos temas, também é válido para a escolha dos docentes. Tem de ser, porém, explicado com toda a clareza, a opinião docente. Nāo podem ser admitidos como docentes aquêles que não estiverem prontos a reconhecer os valores fundamentais da sociedade livre. As- 
sim a universidade recebe em principio tôdas as sugestōes e iniciativas. Estas podem vir dos participantes ou dos grupos sociais. Para a estruturação do plano de trabalho só devem conter fatores objetivos, o que o diretor tem de garantir em planejamento autônomo e responsabilidade própria. Pertence às tarefas organizadoras e ao trabalho da universidade popular tornar visiveis os seus objetivos. Nas condiçōes de participação, que deveriam ser publicadas repetidas vêzes e em Iugar indicado, e na prática da inscrição, a oferta para todos pode ser expressa claramente. Mas além disso, o caráter da universidade popular tem de ser propagado diretamente, por exemplo por meio de relatórios regulares sôbre a composição social, profissional ou o que se refere à idade da assistência, sôbre os temas dos seus interêsses culturais e as suas respostas às ofertas instintivas segundo as estatísticas e os interrogatórios, relatórios que a imprensa local gosta muito de divulgar.

O efeito público desejado para a universidade popular exige também que sejam anunciadas pormenorizadamente os docentes. E importante para a atividade instrutor de adultos mencionar de que origem profissional ou social o docente colheu direito e aptidão para falar sôbre um tema ou de discutí-lo.

A oferta de instrução e os campos de matéria da universidade orientam-se diretamente pela vida espiritual, política, social e prática de cada época. Assim, nenhum aspecto da vida e nenhuma situação do homem é tão pouco importante que não possa ser incorporada ao conteúdo instintivo de uma universidade popular. feita a sugestāo de dispor os planos de trabalho segundo os três aspectos: 1 - Fornecimento de conhecimentos e aptidões do campo da instrução escolar, da antropologia e sociologia, da vida política, reduzidos às condiçōes atuais da atividade de formação de adultos: instrução de linguas estrangeiras faladas e escritas para o que também pode contribuir pedagogicamente o ensino muito discutido da estenografia. 2 - Instrução para o raciocínio sistemático e para a técnica indicada no trabalho espiritual a êste campo de tarefas pertencem também cursos para o acompanhamento da profissão (o não de instrução profissional), para a higiene do corpo e para a prática da vida diária. 3 - Trabalho comum na formação artística e manual de todo o gênero: Aulas práticas e cursos que levam a um aprofundamento da vida espiritual, a uma ocupação diária com os problemas politicos, sociais e culturais e a uma opinião própria fundamentada. O plano de trabalho da universidde popular compreende geralmente formas de organização que servem para as seguintes possibilidades de formação: 1 - Aquisiçāo de conhecimentos fundamentais em cursos de ensino. Aqui pertencem cursos de acompanhamento profissional, cursos de prática da vida e ensino de línguas nos cursos para principiantes. 2 - Promoção da autonomia na atividade por meio de grupos de trabalho. Aqui pertencem nomeadamente as atividades de copiar e de criar, como cantar, desenhar, etc., como também exercícios mais técnicos como fotografar. 3 - Discussōes sôbre problemas 
sociais, politicos, espirituais e religiosos em cursos teóricos e práticos. Aqui pertencem também cursos ligados à universidade, ao tratamento de problemas da vida e cursos de linguas para adiantados se êles ultrapassam o decorar e chegam à discussão objetiva. Importância cultural no trabalho, que sāo chefiados por um perito que expōe e descreve o tema devidamente preparado, o método específico de formaçāo de adultos consiste no estímulo para a discussão livre entre os alunos, que é indispensável. Um outro gênero é a informaçāo por meio de discussōes em fôro, séries de conferências prèviamente elaboradas e conferências livres. Estas servem principalmente para a exposiçāo de novas descobertas cientificas ou de problemas atuais, para os quais o material para cursos e grupos de estudo ainda não foi trabalhado, ou também para a exploração de novos circulos interessados.

No gênero das conferências, que devem servir de impulso para o tratamento sistemático de temas em grupos de trabalho, as séries de continuidade sāo preferiveis as conferências livres. Também nas conferências deve ser admitida pelo menos a informaçāo logo a seguir, se não a discussão. Em casos especiais também podem ser incorporadas no programa da universidade popular formas excepcionais como sessōes de teatro, de cinema, de concêrto e exposiçōes. Também as festas entre os alunos fazem parte dos métodos indicados para a formação de adultos, tendo porem, sòmente sentido na universidade popular, se incluirem um tema de discussão ou uma convivência de um ou mais dias. Nem tôda universidade popular pode incluir tôdas essas formas de reuniōes no seu plano de trabalho. Como das formas excepcionais, também se pode desistir de cursos de especialização e de conferências livres, desde que outras instituiçōes se dediquem suficientemente à sua efetuação. Os grupos de estudo e discussão, que realizam o princípio tradicional metódico do grupo de trabalho, constituem o centro de trabalho da universidade popular. Um tal trabalho de instrução exige várias condições de organização. Isto começa com a qualificaçāo do diretor. Se bem que o instinto filantrópico para a atividade de formação de adultos seja digno de louvor, êle só nāo dá aptidāo para a direçāo duma universidade popular; a êle têm de se juntar uma cultura ampla, o dom de criar conhecimentos nas diferentes disciplinas e talento organizador. É preciso: método sistemático e científico de raciocinar, familiarização com os aspectos espirituais e práticos da política da cultura, da sociologia e pedagogia, assim como, principalmente conhecimento do caráter humano. A liberdade do diretor para o desenvolvimento de um trabalho de instrução planejado nāo deve ser interceptada por elementos nāo competentes. Regulamentos, se êles sāo dados por uma autoridade, qualquer que ela seja, para a estruturaçāo do plano de trabalho tornam logo desde o principio impossivel qualquer planejamento. Para êste é necessária a colaboraçāo dos docentes. Pode ser formado um pequeno grupo que ajuda o diretor sempre no seu planejamento, podem ser promovidas reuniōes gerais dos docentes 
com o diretor, nas quais o plano de trabalho é discutido e esboçado, mas também podem ser dadas para as mãos docentes, sejam êles já colaboradores ou ainda recentes, concepçōes fundadas pelo diretor. O mesmo é válido para a colaboração planejadora com os alunos. preciso pelo menos escutar as sugestōes ou críticas dos alunos ou daqueles que o desejam ser. É indispensável a recepção do diretor ou de seu substituinte. Um bom caminho para a colaboração dos alunos na estruturação do plano de trabalho é a discussāo critica do docente e dos alunos do seu grupo sôbre o programa do período seguinte de trabalho. Ao trabalho de formaçāo planejado faz parte também a aquisição sistemática de uma coleção de livros e outros meios de ensino. Agora é necessário descrever a estrutura exterior e interior segundo a qual se realiza o trabalho da universidade popular, mas também é a condição dêsse trabalho, que o sustenta e o mostra claramente. Um instituto só pode existir se tiver elementos certos de suporte que lhe garanta segurança financeira e existência duradoura, e que lhe dê prestigio. Um fator importante é o municipio cuja tradição representa um suporte para tôda a instituição pública. Mas também se um grêmio de personalidades responsáveis e ligadas à vida pública se encarrega de assumir a responsabilidade para a universidade popular, será preciso guardar a segurança quanto à lei e aos direitos.

Se bem que a subvenção das universidades populares municipais todos os anos seja atualizada, a base financial sempre fica assegurada. Há clareza sôbre a base financeira do seu trabalho de instrução, ela nunca precisa preocupar-se acerca da situaçāo financeira do dia de amanhā. Esta segurança representa o ideal de tôdas as universidades populares, que são sustentadas por grêmios ou grupos formados livremente, para o seu trabalho ela é verdadeiramente indispensável. De igual importância para uma organizaçāo interior forte é que o pessoal para a direção e a gerência da universidade popular receba êsse encargo inequivocamente. Quer o diretor, o gerente e o pessoal de ajuda trabalhem recebendo ordenado, quer trabalhem gratuitamente, têm de ser contratados explicitamente e por algum tempo. Isso dá-Ihes a segurança precisa, como também lhes garante autoridade perante o público. Também em universidades populares menores deve haver uma ordem clara de administração que deve ser orientada segundo principios de organização geralmente seguidos. Tem de haver um arquivo para manter a ordem na correspondência e nos acontecimentos do campo administrativo. Tem de haver uma fiscalização para as contas da casa que segue as ordens geralmente observadas. Para os trabalhos administrativos deverá ser montada em todo o caso uma gerência. Importância e organização interior da mesma resultarão do tamanho da universidade, as possibilidades são muitas, desde o pequeno quarto particular, até a um escritório bem organizado. A gerência também se torna necessária para que o público seja atendido como deve ser. Um horário de trabalho razoável, devidamente anunciado, estabelece ao público a iđéia de que é servido e 
tira o contato dos alunos com a universidade da atmosfera de amabilidade particular, porque é essa a impressāo que se tem na ocasiāo da inscrição, da conversa, da informaçāo, se o diretor ou a gerência é accessível a qualquer horário. O escritório também deve servir de lugar de encontro para o diretor e docentes, ou para os alunos, e é de aconselhar o acréscimo de uma sala de conferência, também para os docentes. É de grande importância que as salas para os grupos de trabalho e para cursos sejam iguais. Embora quase nunca se possa evitar a serventia de aulas de escolas, estas constituem como lugar de trabalho para a universidade um grande problema. Já a sua atmosfera impede o adulto de sentir-se à vontade, e a mobilia não é de forma alguma apropriada. Uma universidade popular não pode progredir se não tiver pelo menos umas poucas salas com mobilia apropriada, que sirvam para os métodos de formação de adultos, como palestras, discussōes, etc. O caráter, a estrutura, o modo de trabalho e a missão universitária exigem severamente um alojamento próprio. Escritório e salas apropriadas sāo o essencial da estrutura exterior de todo o instituto e demonstram claramente a sua existência. Aqui tambem faz parte uma ordem determinada de inscrição e de gratuidade. Os prazos de inscrição deveria ser feita numa atmosfera familiar e nāo como um despacho ou uma venda de bilhetes. Tem de estar presente durante os tempos da inscrição, pelo menos de vez em quando, o diretor para poder dar conselhos. Uma ordem improvisada ou defeituosa é desvantajosa para a propaganda. Ela leva a crer que a universidade popular oferece cultura em particular. Só se pode dizer de caso para caso se deve existir redução de bolsas em geral ou diferentes graus de quantia a pagar. A característica mais importante deve ser o tratamento justo. A universidade não pode deixar de fazer uma propaganda sistemática. O plano de duraçāo para os periodos de trabalho sempre igual contribui tambem muito para a estabilidade exterior da universidade. Em cada lugar se decide individualmente a realização de um, dois ou três periodos de trabalho por ano. Mas em nenhum caso deve-se mudar improvisadamente $e$ fazer reuniōes e cursos oportunamente. Uma exceção, quer dizer, a realização esporádica de uma conferência, de uma excursāo ou o anúncio de um grupo de trabalho fora do plano, só deveria ser feita, se o horário fixo ficar evidente. A manifestaçāo de maior efeito e que melhor faz representar a universidade popular é a publicação regular do plano de trabalho. Por êle se pode verificar as condiçōes de participação regulamentadas, o decorrer contínuo do trabalho, o âmbito e o cenário culturais, ao mesmo tempo êle demonstra o estilo da propaganda de uma universidade popular. Se esta deixar de publicar êsse plano, falta-lhe uma caracteristica decisiva de sua qualidade. Também não se pode deixar de concluir pormenores no seu plano de ação. A universidade popular nāo deve seguir como modèlo a lista das preleçōes da escola superior, porque ai nāo se recebe informaçōes sôbre um ato de formaçāo de adultos, precisa também, já na sua elaboração, da animação, da curiosidade pelo tema, ela precisa também 
de pelo menos uma alusão às idéias dentro das quais se vai desenvolver o grupo de trabalho ou o curso. Só então é respeitado o princípio de que o aluno deve se decidir livremente para a participação. Assim o plano de trabalho torna-se um produto espiritual de alto grau; para a sua redação necessita-se arte e fôrça de expressāo para resumir devidamente. Ela constitui um dos mais importantes fatores da colaboraçāo entre os docentes e a direção da universidade popular. O trabalho é o cartão de visita do espirito que rege a universidade popular. Além disso êle é com os seus anúncios resumidos o espêlho dos problemas atuais que comovem a população de cada lugar. A coleção dos planos de trabalho das universidades populares alemās são um resumo das idéias e ações na vida particular e na vida comum do presente para isso deve ser 0 desejo de tôda a universidade popular. 